\title{
RETRATOS DO EMPREENDEDORISMO ÉTNICO-RACIAL: UM ESTUDO SOBRE A TRAJETÓRIA DE EMPREENDEDORES NEGROS
}

Alex Fernando Borges ${ }^{1}$

Alessandro Gomes Enoque ${ }^{1}$

Ramon Mica Neto ${ }^{1}$

Felipe Hernandes Rissi ${ }^{1}$

${ }^{1}$ Universidade Federal de Uberlândia 


\section{RETRATOS DO EMPREENDEDORISMO ÉTNICO- RACIAL: UM ESTUDO SOBRE A TRAJETÓRIA DE EMPREENDEDORES NEGROS}

Resumo: O objetivo deste artigo consistiu em analisar a trajetória de dois empreendedores negros que atuam em uma cidade da região do Triângulo Mineiro. Foi possível observar que, associado a um processo empreendedor marcado por processos de identificação e exploração de oportunidades diversos, houve um histórico de preconceito racial que permeou as experiências vividas pelos dois empreendedores nos diversos espaços sociais que frequentaram (escola, trabalho, família). Foi somente a partir de um processo de autorreflexão que os mesmos puderam aceitar-se enquanto negros, buscando expandir tal compreensão para o universo de seus negócios. Tais negócios, que parecem mesclar em si um caráter de luta e de valorização da cultura negra, apresentam novas formas de concorrência real e simbólica, focando seus esforços em direção a um determinado público específico (negro). O preconceito racial parece, no entanto, perseguir tais empreendedores mesmo no cotidiano de suas empresas gerando sentimentos contraditórios de luta/pessimismo/resignação quanto ao futuro.

Palavras-chave: Empreendedor. Processo Empreendedor. Raça. Análise de Discurso.

\section{$1 \quad$ Introdução}

A temática do empreendedorismo tem estado presente, de maneira marcante, no vocabulário de diversas áreas do conhecimento científico, incluindo o campo da Administração (LOPES; LIMA, 2019). Tal repercussão é, em grande parte, credora de um crescimento numérico de tal atividade no Brasil e no Mundo. De acordo com dados do Global Entrepreneurship Monitor (GEM), existem atualmente no Brasil cerca de 50 milhões de empreendedores, número este que posiciona o país entre os primeiros países do ranking de empreendedorismo (GEM, 2018) e que ilustra o impacto da atividade empreendedora sobre a economia e sua capacidade de intervenção no ambiente de negócios (VALE, 2014).

Neste sentido, a busca pela compreensão e explicação das especificidades do fenômeno do empreendedorismo passa pela problematização teórica e empírica de suas diferentes possibilidades de manifestação (BORGES; LIMA; BRITO, 2017; CARLSSON et al., 2013), que englobam desde questões objetivas - como mensurações quantitativas de suas repercussões econômicas, de inovações, de perfil e comportamento empreendedor - até questões subjetivas - como o processo empreendedor, o intraempreendedorismo, a ação empreendedora e a inserção de discussões sobre questões sociais, individuais, discursivas, que são usualmente pertinentes aos estudos organizacionais (BUSENITZ et al., 2014). Não obstante, existem lacunas na literatura, que apontam a necessidade de se compreender, de forma mais aprofundada, toda a dinâmica e complexidade do empreendedorismo. Há, então, demanda por estudos que valorizem a diversidade e amplitude que o referido fenômeno pode assumir na prática, incluindo aí evidências sobre as particularidades de sua manifestação em torno de questões étnicas, raciais, de gênero, dentre tantas outras. 
Sendo assim, este artigo pretende agregar novas evidências a um debate pouco explorado no campo de estudos sobre o fenômeno empreendedor, que pode ser caracterizado como empreendedorismo étnico-racial, empreendedorismo de minorias, ou ainda empreendedorismo negro (black entrepreneurship). Trata-se de uma temática que procura problematizar a natureza e as particularidades da ação empreendedora de indivíduos negros, vinculando aspectos de suas trajetórias a elementos tradicionais da pesquisa em empreendedorismo (HISRICH; BRUSH, 1991; HARVEY, 2005; KÖLLINGER; MINNITI, 2006; SINGH; GIBBS, 2013; GIBBS, 2014; REZENDE; MAFRA; PEREIRA, 2018).

Neste sentido, verifica-se a relevância do tema aqui abordado, valorizando como é dinâmica e particular a realidade do empreendedorismo étnico-racial em contextos específicos, como é o caso brasileiro. Diante disso, procura-se, neste artigo, obter respostas ao seguinte problema de pesquisa: quais são as particularidades da manifestação do empreendedorismo étnico-racial, em especial daquele relacionado à trajetória de empreendedoras e empreendedores negros? Para responder este questionamento, o objetivo geral deste trabalho consiste em analisar a trajetória individual e empresarial de dois empreendedores negros que atuam em uma cidade na região do Triângulo Mineiro, estado de Minas Gerais. Especificamente, busca-se: a) compreender o processo empreendedor executado por empreendedores negros para criar e desenvolver seus negócios; b) identificar os desafios e dificuldades da ação de empreendedores negros no mercado local.

Busca-se, com o desenvolvimento deste artigo, lançar luzes sobre uma problemática pouco explorada nos estudos organizacionais (CONCEIÇÃO, 2009; ROSA, 2014), no mundo empresarial (JAIME, 2017) e nos estudos em empreendedorismo (SINGH; GIBBS, 2013; REZENDE; MAFRA; PEREIRA, 2018). Trata-se de um cenário rico que merece ser investigado e que oportuniza pesquisas e reflexões sobre a importância da questão étnicoracial para o campo do empreendedorismo (HISRICH; BRUSH, 1991; HARVEY, 2005; KÖLLINGER; MINNITI, 2006; GIBBS, 2014). A problematização do empreendedorismo étnico-racial gera impactos no sentido da identificação de histórias e trajetórias de empreendedores que abrem suas empresas e que enfrentam desafios relacionados à questão étnico-racial. Esses desafios, certamente, contribuem cientificamente e agregam evidências adicionais a uma incipiente, porém rica, literatura, possibilitando assim a compreensão, de um modo mais aprofundado e consistente, da dinâmica do empreendedorismo e da criação de negócios por parte de empreendedoras e empreendedores negros.

\section{Empreendedorismo, processo empreendedor e empreendedorismo étnico-racial}

O empreendedorismo tem se caracterizado por múltiplas abordagens e pela exploração de diferentes de perspectivas teóricas e metodológicas (LOPES; LIMA, 2019; VALE, 2014). A amplitude desse campo pode ser observada por meio da variedade de estudos, publicações e eventos especializados sobre o tema (FILION, 1999b; GARTNER, 2012). Com efeito, diferentes pesquisadores têm buscado identificar os limites e as fronteiras de análise do empreendedorismo, observando-se uma busca pelo estabelecimento de definições para termos como empreendedorismo e empreendedor, pela identificação e delimitação de diferentes tipos de empreendedorismo, pela compreensão de suas características e implicações, dentre outras possibilidades (BORGES; LIMA; BRITO, 2019). 
Neste sentido, alguns aspectos delimitadores do campo do empreendedorismo precisam ser apresentados e discutidos, de modo a subsidiar o entendimento de algumas particularidades associadas a esse fenômeno. Inicialmente, torna-se interessante ressaltar que o empreendedorismo se estrutura a partir de uma vinculação de origem, envolvendo a relação entre as concepções de empreendedorismo e empreendedor. De um lado, tem-se a configuração de um fenômeno (empreendedorismo) que apresenta implicações econômicas e sociais, sobretudo associadas à abertura de novos negócios e criação de novos produtos e serviços (GARTNER, 2012). De outro, tem-se a figura central do agente (empreendedor) enquanto responsável principal pela reunião de recursos, exploração de oportunidades e realização do empreendimento (FILION, 1999a; FILION, 1999b). Assim, o fenômeno do empreendedorismo envolve a presença de um agente que promove uma intervenção em uma determinada realidade econômica e social, seja por meio da abertura de um novo negócio, da criação de um novo produto/serviço, da exploração de fonte de matéria-prima, ou da implantação de melhorias em organizações, produtos ou serviços já existentes (GOMES; LIMA; CAPPELLE, 2013). O empreendedor seria, então, reconhecido como uma pessoa criativa, hábil para estabelecer e atingir objetivos e capaz de interpretar o ambiente e detectar nele novas oportunidades de negócio (PAIVA JR, 2004).

Diante deste cenário, surgem diversas concepções e abordagens que buscam compreender e explicar a natureza e a lógica de manifestação do empreendedorismo, dentre as quais destaca-se a visão de empreendedorismo como processo. Tal abordagem possibilita a promoção de uma mudança de foco do campo do empreendedorismo, na medida em que a preocupação estaria mais direcionada para aquilo que o empreendedor efetivamente faz, e não naquilo que o indivíduo que ele é ou representa (LIMA, 2010; WATSON, 2013). Assim, a noção de empreendedorismo reflete a configuração de uma abordagem que permite a análise de elementos que delimitam a noção de processo empreendedor (MOROZ; HINDLE, 2012).

Shane e Venkataraman (2000) definem o processo empreendedor como uma sequência dinâmica de etapas, envolvendo desde aspectos como as características do indivíduo empreendedor, fatores contextuais, a existência e a identificação de oportunidades de negócios, e a exploração dessas oportunidades através da criação de novos empreendimentos. Tem-se, então, uma alternativa de compreensão e explicação do empreendedorismo, inclusive reverberando em sua própria definição, que busca responder a um questionamento central: "como, por quem, e com quais efeitos as oportunidades de criação de produtos e serviços são descobertas, avaliadas e exploradas" (SHANE; VENKATARAMAN, 2000, p. 218).

Partindo do desenvolvimento teórico-conceitual proposto por Shane e Venkataraman (2000), diversos autores procuraram explorar a temática do processo empreendedor, elaborando conceitos para uma visão processual do empreendedorismo (LEYDEN; LINK, 2015). A noção de processo empreendedor contempla funções, atividades e ações individuais e/ou coletivas voltadas para a identificação de oportunidades e a criação de (novos) negócios como resposta a essas oportunidades (BYGRAVE, 2007; JACK; ANDERSON, 2002). Logo, o processo empreendedor passa a ser interpretado como um processo construído a partir de uma natureza cumulativa de etapas de utilização e exploração de recursos que converge para a criação de um novo empreendimento através de uma ideia, de estudos de viabilidade conceitual do negócio, da delimitação do empreendimento e do início de suas atividades e operações (HABER; REICHEL, 2007). 
Portanto, o debate sobre processo empreendedor contempla o nexo entre a ação de indivíduos empreendedores e a estruturação e exploração de oportunidades de negócio (DAVIDSSON, 2015; ECKHARDT; SHANE, 2003; SHANE, 2012). De acordo com essa perspectiva, os empreendedores seriam indivíduos que, orientados por suas ideias e motivações, delimitam processos de criação de negócios através da identificação de oportunidades (JACK; ANDERSON, 2002). Trata-se de valorizar o papel desempenhado por essas motivações na orientação de situações de abertura de empresas (HESSELS; VAN GELDEREN, THURIK, 2008), e de ressaltar os atributos pessoais dos empreendedores nesse processo (NASSIF; GHOBRIL; SILVA, 2010). Logo, a partir deste quadro teórico, pode-se lançar luzes sobre realidades ainda pouco exploradas no campo de pesquisas, como aquelas marcadas por questões culturais, religiosas, familiares, étnico-raciais, dentre tantas outras.

Atualmente, pode-se afirmar que a participação de negros ainda é pouco compreendida pelas pesquisas sobre empreendedorismo (CRUZ; FALCÃO, 2016). Os estudos sobre o tema exploram questões como o comportamento de empreendedores negros (HISRICH; BRUSH, 1991), as diferenças entre empreendedoras brancas e negras (INMAN, 2000), a relação entre raça e gênero na intenção empreendedora (HARVEY, 2005), as diferenças entre empreendedores negros e brancos (SULLIVAN, 2007), os desafios enfrentados por empreendedores negros nos Estados Unidos (KÖLLINGER; MINNITI, 2006), na África do Sul (PREISENDÖRFER; BITZ; BEZUIDENHOUT, 2012) e no Brasil (OLIVEIRA; PEREIRA; SOUZA, 2013), o reconhecimento de oportunidades por empreendedores negros (SINGH; GIBBS, 2013), as questões de gênero e as diferenças entre empreendedoras e empreendedores negros (GIBBS, 2014), a participação de empreendedoras negras em processos de criação de negócios (ARMAN, 2015), e a construção social da identidade de empreendedores negros (REZENDE; MAFRA; PEREIRA, 2018). Em síntese, esses estudos demonstram histórias e trajetórias de empreendedoras e empreendedores negros que não se encontram exclusivamente associadas a questões objetivas do empreendedorismo e das práticas de criação e desenvolvimento de negócios a ele vinculadas, mas também a situações de discriminação e de preconceito social, que se manifestam a partir da interação com diversos agentes do ambiente institucional e empresarial, envolvendo atores do poder público, concorrentes, clientes e fornecedores, por exemplo.

Assim, embora sejam encontradas evidências sobre a relevância das questões étnicoraciais no âmbito mais amplo dos estudos organizacionais, em discussões sobre temáticas como diversidade (ALVES; GALEÃO-SILVA, 2004; COSTA; FERREIRA, 2006; FLEURY, 2000), como a inserção do negro no mundo empresarial (JAIME, 2016) e no mercado de trabalho (CERQUEIRA, 2012), como as discussões sobre a questão racial do ponto de vista teórico (CONCEIÇÃO, 2009; ROSA, 2014), da gestão de pessoas (MONTEIRO, 1989), de gênero (ARMAN, 2015), e de carreira gerencial (COELHO JÚNIOR, 2011), a relativa escassez de publicações sobre o tema no campo do empreendedorismo demonstra a necessidade de se realizar estudos adicionais que permitam melhor compreender essa problemática. Assim, o presente artigo procura explorar essa lacuna de investigação, oportunizando uma maior compreensão dessa realidade em um contexto particular. 


\section{$3 \quad$ Procedimentos metodológicos}

Para o desenvolvimento da presente pesquisa, optou-se pelo uso de uma abordagem de investigação de caráter qualitativo. Corbin e Strauss (2008, p.24) definem a pesquisa qualitativa como um "[...] processo não-matemático de interpretação, feito como objetivo de descobrir conceitos e relações nos dados brutos e de organizar esses conceitos e relações em um esquema explanatório teórico". Para Denzin e Lincoln (2006, p.17) "a pesquisa qualitativa envolve o estudo do uso e coleta de uma variedade de materiais empíricos (...) que descrevem momentos e significados rotineiros e problemáticos na vida dos indivíduos".

Com base no método qualitativo, foi desenvolvido um estudo multicaso, envolvendo a realização de uma investigação em profundidade junto a duas organizações situadas na cidade de Ituiutaba, região do Triângulo Mineiro, estado de Minas Gerais, criadas e lideradas por empreendedores negros. Yin (2001, p. 32) define a estratégia metodológica de estudo de caso como "uma investigação empírica que investiga um fenômeno contemporâneo dentro de seu contexto da vida real, especialmente quando os limites entre o fenômeno e contexto não estão claramente definidos". Assim, a combinação dos dois casos em um mesmo movimento de investigação pode ser caracterizada como "estudo multicaso" ou "estudos de casos múltiplos".

$\mathrm{O}$ processo de coleta de dados envolveu o recurso à técnica de entrevistas em profundidade. Foram entrevistados os empreendedores que se vinculam às empresas estudadas, escolhidos fundamentalmente com base na participação e no posicionamento competitivo ocupado atualmente no mercado, e na inserção dentro da perspectiva do empreendedorismo étnico-racial. Para esta seleção, partiu-se da constatação de uma realidade diversa, composta por mais de 50 empresas criadas e lideradas por empreendedores negros em uma cidade fortemente influenciada por cultura afrodescendente (BORGES et al., 2016), fato que oportunizou a seleção dos casos estudados e que justificou o esforço de compreensão da realidade observada a partir dos dois casos selecionados.

As entrevistas foram orientadas por um roteiro, que buscou problematizar a trajetória desses empreendedores e das empresas por eles criadas. $\mathrm{O}$ roteiro foi elaborado com base no quadro teórico sobre empreendedorismo, no conceito de processo empreendedor, e nas evidências teóricas e empíricas sobre empreendedorismo étnico-racial, procurando sempre apresentar aderência em relação aos objetivos da pesquisa. As entrevistas foram gravadas em dispositivo eletrônico e transcritas em seu inteiro teor em sofware de processamento de texto, contribuindo assim para o rigor do método de investigação qualitativa. Os nomes de indivíduos e negócios foram suprimidos, de modo garantir o sigilo das informações prestadas.

A partir da transcrição do material empírico coletado, os dados foram posteriormente analisados, com base na técnica de análise de discurso (FIORIN, 2014; PÊCHEUX, 2014; CHARAUDEAU; MAINGUENEAU, 2014; LEEUWEN, 2008). O objetivo principal de se utilizar a análise de discurso consiste em compreender, em profundidade, os discursos dos empreendedores entrevistados e articulá-los de forma a compor com os objetivos do estudo. Pretende-se, através do emprego da referida técnica de análise, identificar, nos dados e narrativas coletadas, evidências que permitam associar a ação e o cotidiano dos indivíduos empreendedores com as temáticas abordadas no estudo, incluindo os desafios relacionados com o processo de criação de seus negócios tanto do ponto de vista empresarial, como também do ponto de vista étnico-racial. 


\section{Empreendedorismo étnico-racial: retratos de sua manifestação nas decisões e ações de empreendedores negros}

\subsection{Processo empreendedor de criação de negócios: a ação de empreendedores negros}

A empresa A - uma organização do ramo de barbearias - atua desde fevereiro de 2018 na cidade de Ituiutaba-MG. Com um número total de cinco funcionários, a empresa originouse a partir do momento em que o empreendedor A, que se autodeclara negro, decidiu sair de uma franquia também do ramo de barbearias, em que atuava como funcionário. A ideia para a abertura do novo negócio é derivada, em parte, de um histórico de discriminação e preconceito sofrido pelo empreendedor, praticado por seu antigo patrão em decorrência de sua raça. Cansado de tal realidade, magoado e com o objetivo de provar sua real capacidade, o empreendedor A estabeleceu contato por e-mail (e sem expectativas) com o franqueador da rede de barbearias da qual faz parte. O processo de negociação durou cerca de quatro meses, culminando com a abertura da loja em uma avenida de grande circulação da cidade pesquisada.

Com base nessa ideia inicial, tem-se o início do processo de identificação e exploração de oportunidades de negócio. Por ter experiência anterior no ramo, o empreendedor A identificou uma oportunidade de posicionar seu negócio de forma a atender ao público negro (inclusive aqueles de classe social mais baixa), através de uma experiência inovadora em seu setor de atividade e até então inexistente no mercado local. Foram, então, executadas iniciativas para explorar essa oportunidade. Percebendo que o ramo de barbearias estava em crescimento, e considerando que seus concorrentes possuíam uma atuação muitas vezes uniformizada, o empreendedor A buscou um ambiente diferenciado, com a instalação de mesa de sinuca, venda de bebidas alcóolicas, cadeiras massageadoras, televisão, videogames, shows acústicos e som ambiente. O clima de festa constante tem, por objetivo, atrair uma clientela jovem que se encontrava farta dos serviços de barbeiros e barbearias tradicionais. Além disso, como parte de sua estratégia de se posicionar como uma barbearia moderna que atende um público jovem e negro, o empreendedor A contratou auxiliares (também negros) de forma a criar uma identidade e marca voltada para este público. Pautado em uma gestão participativa, o empreendedor A vem, ao longo do tempo, incluindo novos serviços em sua barbearia, como eventos de $e$-sports e sinuca e serviços de tatuagem.

A empreendedora $\mathrm{B}$, mulher e negra, iniciou as atividades de sua empresa em agosto de 2017. A ideia para a abertura do empreendimento surgiu a partir da necessidade de a empreendedora ampliar as atividades de seu ateliê de costura que funcionava nos fundos de sua casa. O novo negócio foi aberto no centro da cidade pesquisada em fevereiro de 2018 , com foco direcionado para a comercialização de produtos com estampas africanas e voltados para o público negro, como brincos, roupas, colares, bolsas, canecas, turbantes, bonecas, dentre outros. Inspirada por uma transformação pessoal (onde cortou bem curto os cabelos, buscando assumir suas raízes africanas) e por uma história de preconceito com sua filha, a empreendedora A direcionou suas atividades para o público negro, identificando uma oportunidade de negócio fundamentada na inexistência de concorrentes no mercado local e em um público alvo que demandava esses tipos de produtos. Com isso, foi possível explorar essas oportunidades através da comercialização de produtos voltados ao público negro, 
associada a um objetivo de promover e valorizar a beleza negra, carregando consigo uma missão de valorizar o empoderamento feminino/negro.

Neste sentido, nota-se a configuração de um conjunto de ações do empreendedor e da empreendedora, ambos negros, na construção de seus novos negócios. Trata-se de atividades desenvolvidas no sentido de viabilizar a criação de novos empreendimentos, focados em ideias voltadas ao atendimento de um mercado consumidor específico em uma cidade com forte cultura e tradições da população negra. Neste cenário, verificam-se influências diversas dessas ideias e motivações na dinâmica de processos de identificação de oportunidades em seus respectivos ramos de atuação específicos, que convergiram para a exploração dessas oportunidades através da criação de negócios que associam, em uma mesma perspectiva, tanto elementos objetivos - incluindo a comercialização de produtos, a prestação de serviços, o atendimento das necessidades e expectativas dos consumidores, e a busca por competitividade e sobrevivência no mercado - como elementos subjetivos - incluindo a relação entre a atividade empreendedora e a questão étnico-racial, a exploração de oportunidades vinculadas ao empreendedorismo negro e ao negócio voltado a este público-alvo específico, e também a presença de desafios desses empreendedores negros no contexto da ação empreendedora no mercado local.

\subsection{Desafios de empreendedores negros no empreendedorismo étnico-racial}

Como exposto anteriormente, o processo empreendedor executado pelos empreendedores estudados permite a observação da delimitação de decisões e ações relacionadas ao surgimento de ideias para a abertura de empresas, e de decisões e ações associadas ao processo de identificação e exploração de oportunidades de negócios. No entanto, para uma análise mais compreensiva do empreendedorismo étnico-racial, é preciso levar em consideração não somente os aspectos objetivos vinculados ao fenômeno empreendedor, mas também as questões subjetivas pertinentes à atuação de empreendedores negros em um contexto social, histórico, econômico e empresarial marcado por desafios diversos.

A seleção lexical do fragmento discursivo (001) associa, explicitamente, a figura do sujeito-enunciador a um histórico de discriminação racial que o acompanha desde os tempos de escola. Neste espaço social, carregado de sofrimento ("a gente sofre na escola"), o enunciador parece ter sua identidade negada ("você nunca tem nome quando você é preto") e substituída, por parte de personagens implícitos como os colegas de turma, por uma série de apelidos pejorativos e discriminatórios ("você é o negrinho, pretinho, petróleo e os demais apelidos"). É importante destacar, ainda, neste sentido, a utilização de tais "apelidos" em seu formato diminutivo como "negrinho" e "pretinho", como uma estratégia intencional por parte dos colegas de escola na direção de tentar diminuir o sujeito-enunciador e colocá-lo em uma posição social inferior. Tal realidade parece ter tido impactos diretos na aceitação (ou não) de sua própria raça por parte do empreendedor A. Neste sentido, o mesmo utiliza-se, em diversos momentos da entrevista, de um discurso que nega duplamente sua própria condição racial, na medida em que afirma não querer ser negro e se ver como branco ("eu nunca quis ser preto", "eu sempre me via branco"): 
(001) (...) eu nunca quis ser preto, pela discriminação que a gente sofre na escola. Porque na escola você nunca tem nome quando você é preto, você é o negrinho, pretinho, petróleo e os demais apelidos. Com isso eu nunca quis ser preto, eu sempre me via branco, no decorrer do tempo eu descobri que o errado não era eu ser negro era a mentalidade dos outros. Aí eu passei a assumir o meu lado preto, vamos falar assim, aí eu mesmo quebrei vários preconceitos que tinham dentro de mim. Porque preto não podia ter tatuagem, porque não destaca, preto não pode usar uma roupa de cor, porque senão vira sinaleiro, que eram coisas que vinham de avó para mãe, de mãe para filho. (Empreendedor A)

Esta dura realidade, vivenciada pelo sujeito-enunciador não tão somente na escola, mas, também, em outros espaços sociais como o trabalho, fez com que o mesmo passasse, ao longo do tempo, por um processo de autorreflexão e autoconscientização ("no decorrer do tempo, eu descobri que o errado não era eu ser negro, era a mentalidade dos outros") que parece ter culminado com um processo de auto aceitação. É sintomático, neste sentido, a utilização, por parte do empreendedor A de expressões como "eu passei a me assumir" ou "eu ainda passei mais um tempo bem preso mesmo com essa parte negra". Convêm destacar, ainda, que, no caso específico do empreendedor A, que atua na atividade de barbearia, o assumir parece possuir um triplo significado simbólico na medida em que o mesmo passou a não somente ver-se enquanto negro, mas, também, a reforçar sua identidade visual através da utilização de penteados, tatuagens, entre outros. Além disto, é importante destacar que a profissão de barbeiro, em nossa sociedade, normalmente tem uma representação social relacionada a homossexualidade. Neste sentido, o "assumir" por parte do sujeito-enunciador, parece englobar, em si, não somente a aceitação da sua raça, mas, também, dos estereótipos associados à sua profissão:

(002) Eu ainda passei mais um tempo bem preso mesmo com essa parte negra né, tentando ser branco, coisa que não dava para ser. E não tem muito tempo que eu $\underline{\text { assumi }}$, que eu comecei a assumir deve ter mais ou menos uns 5 anos que eu passei a ser preto. Até então quando a gente fazia qualquer coisa que tinha que falar sua cor eu nunca coloquei negro, eu sempre colocava qualquer coisa menos preto. Aí eu comecei a assumir, foi aí que eu comecei a ter cabelo, comecei a fazer tatuagem, mudar meu estilo. (Empreendedor A)

Este processo de negação/transição/aceitação parece estar presente, também, no discurso empreendido pela empreendedora B. Conforme pode ser visto nas seleções lexicais dos fragmentos discursivos (003) e (004), a transição ("comecei a fazer a transição, foi uma mudança que eu falo de dentro para fora", "só quem passa pela transição que sabe o que é isso") parece estar acompanhada não tão somente de um processo de autorreflexão por parte da mesma, mas, também, de uma mudança em seu visual ("a transição é quando você tem o cabelo afro e está fazendo o processo químico né, sempre deixando liso, e resolve voltar pro original que é o seu cabelo afro"). Nesta perspectiva, parece ser simbólico o corte bem curto do cabelo como uma representação metafórica de um novo começo (de uma nova vida). Além disto, este aceitar-se parece buscar amparo, também, e como pode ser visto na seleção lexical do fragmento discursivo (004) em um determinado ethos religioso. As diversas referências a Deus (não somente no uso próprio da palavra, mas, também, como sendo "Ele") parecem demonstrar que a aceitação com sua própria raça esteja ancorada, em parte, nas 
representações que a empreendedora $\mathrm{B}$ tem acerca de sua religião, como um todo, e da divindade, em particular ("Deus fez cada um de uma forma. Ele. Ele. Eu acho que Ele não ia criar nada que fosse ruim"):

(003) a ideia surgiu porque quando eu cortei meu cabelo, comecei a fazer a transição, foi uma mudança que eu falo de dentro pra fora, né. Então assim, não foi só cortar o cabelo, mudou tudo né, o fato que só quem passa pela transição que sabe o que é isso. A transição é quando você tem o cabelo afro e está fazendo o processo químico né, sempre deixando liso, e resolve voltar pro original que é o seu cabelo afro. Então pra tirar toda a química, a gente corta o cabelo, isso se chama big chop, eu fiquei com o cabelo bem curto, bem curto mesmo. (Empreendedora B)

(004) (...) é porque assim, eu acho que é me aceitar né? Porque eu acho que assim, na fase da adolescência a pessoa quer muito assim, mostrar pro outro que é bonita, ai a beleza as vezes é aquela beleza artificial, então a gente põe mega hair, a gente coloca tanta coisa pra agradar o outro, e hoje eu já me amo do jeito que eu sou, então eu acho que as pessoas tem que me aceitar assim, do jeito que eu sou, com cabelo afro, com os lábios grossos, as vezes com nariz de fusquinha, e é assim que eles tem que me aceitar, eu não tenho que mudar para as pessoas me aceitar, né. Porque eu acho que assim, Deus fez cada um de uma forma, Ele, Ele, eu acho que Ele não ia criar nada que fosse ruim. (Empreendedora B)

Este processo de transformação parece estar relacionado não tão somente as representações sociais do empreendedorismo por parte dos entrevistados, mas, também, a visão de que tais empreendimentos são, de alguma forma, "extensões" desta mudança em direção a comunidade. Ao observarmos as seleções lexicais dos fragmentos discursivos (005), (006), (007), (008) e (009), há um claro sentimento de que tais empreendimentos possuem uma missão maior que ultrapassa certa racionalidade de natureza econômica ("eu não preocupo tanto com o lucro"). Neste sentido, o empreendimento apresenta-se, algumas vezes, como representação de uma luta social maior ("a loja não é só uma loja né... é um grito né, é um grito isso daqui", "esse trabalho aqui é um trabalho bandeirante, de luta") e, em outras, como um locus de valorização da cultura negra ("isso aqui é um trabalho para que elas se amem do jeito que elas são", "para que elas se aceitem", "para que elas se valorizem"):

(005) Então assim, foi muita coisa, foi trabalhando em nós, que surgiu assim, eu falo que esse trabalho aqui é um trabalho bandeirante, de luta, eu não preocupo tanto com o lucro, sim, eu sou comerciante, então eu tenho que ganhar. Mas igual assim, eu falo pras negras, isso aqui é um trabalho para que elas se amem do jeito que elas $\underline{\text { são, }}$ né, para que elas se aceitem, para que elas se valorizem. Se olha no espelho e fala, não, eu sou bonita sim, eu vou chegar.... Agora eu tenho a consciência que eu posso ser né? (Empreendedora B)

(006) (...) a loja não é só uma loja né... é um grito né, é um grito isso daqui. (Empreendedora B)

É importante destacar, ainda, que a utilização de determinados substantivos como, por exemplo, "luta" e "grito", diretamente relacionados ao empreendimento, parece reforçar a posição do empreendedor negro em contraposição ao discurso hegemônico na sociedade, qual $\underline{\text { seja, o de que o negro não poderia ser empresário, mas, somente, trabalhador ("o negro não }}$ 
foi feito para ser empresário, não foi feito para ser dono de nada, foi feito para ser trabalhador"). O indivíduo falaria, neste sentido, a partir de uma posição social na qual o "gritar" e o "lutar" seriam, portanto, lugares comuns:

(007) A ideia de trazer a (barbearia) para cá foi, porque eu saí do outro emprego muito magoado com o pessoal de lá por uma discriminação racial que eu sofri e resolvi abrir uma concorrência. (Empreendedor A)

(008) E por mais que a gente tente, vamos falar superar, passar por isso, as privações são muito grandes até hoje em cima do negro. $\underline{O}$ negro não foi feito para ser empresário, não foi feito para ser dono de nada, foi feito para ser o trabalhador. (Empreendedor A)

(009) Tanto é que eu mantive a minha barbearia bem "black", era para ser três negros, eu deixei um meio pardo só para dar uma disfarçada, mas a ideia é bem preto mesmo. (Empreendedor A)

Um outro ponto que merece ser destacado a partir do fragmento (007) é o da utilização da discriminação sofrida (seja no ambiente escolar ou em outros trabalhos) como motivação para criação do empreendimento. Tal discurso, presente não somente no empreendedor A, mas, também, na empreendedora $\mathrm{B}$, abre espaço para uma discussão que amplie as razões culturais pelas quais determinados negócios são abertos no Brasil. Além disto, possibilita, também, uma discussão mais aprofundada acerca das formas simbólicas de competição entre empresas (não somente uma competição de natureza econômica).

Assim, uma das principais estratégias utilizadas pelos empreendedores pesquisados para se inserir no mercado diz respeito, exatamente, a focar no público negro, conforme pode ser observado nas seleções lexicais dos fragmentos discursivos (010) e (011):

(010) Porque aqui se for parar para ver a fundo mesmo os negros donos são pouquíssimos né, pouquíssimos mesmo. Tem eu que sou dono de uma barbearia, a (...) que é dona de uma loja de artigo "black", se for para você parar para pensar quem é dono do seu próprio negócio é dono voltado para o negro. (Entrevistado A)

(011) E aí a gente começou, pensava em trabalhar só com brincos e turbantes, mas aí surgiu bolsas, surgiu roupa, surgiu assim, vários tipos de coisas, colares né, pulseiras, brincos, então tudo veio de uma vez, e a gente abriu a (...) lá na minha casa, e conseguimos atingir um público mais afro, até então, inicialmente afro. Então nosso público era noventa por cento, ou noventa e cinco por cento de negros, cinco por cento branco. (Empreendedora B)

Há, também, por assim dizer, um certo direcionamento dos empreendimentos no sentido de buscar atender as necessidades específicas deste público. Tais ações parecem ir, desde a contratação de funcionários negros (009), passando pela comercialização de produtos étnicos (bonecas negras, vestidos e canecas com estampas africanas, turbantes, entre outros fragmento (012)) e pela criação de um ambiente de atendimento acolhedor a este público (mesmo que de classe social mais baixa - fragmento (013)), culminando com a valorização de uma estética e de uma identidade negras: 
(012) Hoje eu vejo assim que o resultado tá sendo muito positivo, né, as pessoas mesmo falam muito no nome da loja, até assim, igual eu te falei, na parte da aceitação, né, o pessoal aceitou bem, e também a pessoa quando chega aqui e vê que tudo parece com ela, né, igual eu falo o negro, tem umas que choram, elas ficam emocionada porque tem boneca negra, tem vestido com estampas de negro, caneca com estampa de negro, brincos, né, tem tudo relacionado para elas, então elas falam assim, eu nunca me senti tão bem em um lugar quanto aqui, né, eu me sinto assim, realizada estando aqui dentro. (Empreendedora B)

(013) O maior problema é que a gente tem que quebrar essa discriminação. "É chique, eu não vou". "Eu não vou lá, porque estou sujo". "Porque sou servente, porque sou pedreiro". "Porque meu trabalho é braçal". Eu tenho clientes que eles deixam para cortar o cabelo no sábado após o almoço, porque já foram em casa, já tomaram banho, já trocaram de roupa para vir no ambiente. E a nossa ideia não é essa, a gente está vindo com várias propagandas novas para quebrar um pouco disso. (Empreendedor A)

Argumentado acerca do principal desafio que o mesmo enfrentou para empreender, o entrevistado A aponta a cor da pele como elemento principal ("não existe mais nenhum desafio, só a cor da pele"). Tal realidade, no entanto, parece não ser impeditiva para que os desafios sejam enfrentados em seu dia-a-dia, uma vez que os empreendedores pesquisados parecem estar preparados não só pela sua formação, mas, também, pela própria rudeza do ser negro. É sintomático, neste sentido, a seleção lexical do fragmento discursivo (015) que faz certa alusão a temática da escravidão ao evocar a figura explícita do chicote ("a gente já veio com um couro mais grosso, o negro ele tem um couro mais grosso, pra suportar mesmo a chicotada"):

(014) A cor da pele. Não existe mais nenhum desafio, só a cor da pele. (Empreendedor A)

(015) (...) a gente já veio um couro mais grosso, o negro ele tem um couro mais grosso, pra suportar mesmo a chicotada... A gente já está preparado para isso, é como se tivesse um escudo protetor, né... Tem que estar, porque se não tiver não, sofre. (Empreendedora B)

O "escudo protetor" parece não fazer desaparecer, no entanto, uma realidade discriminatória que acompanha o dia-a-dia da atividade empresarial dos entrevistados. Conforme pode ser visto nas seleções lexicais dos fragmentos discursivos (016) e (017), o empreendedor A parece demonstrar certo sentimento de pessimismo quanto as possibilidades de modificações estruturais nas representações que o negro, em geral, e o empreendedor negro, em especial, em nossa sociedade. Para tanto, o empreendedor A faz uso de uma frase popular ("só se Deus voltar, Jesus Cristo voltar para a Terra") para demonstrar que esta cultura racista brasileira tenderia a permanecer por um longo período de tempo:

(016) Eu vejo até hoje que chegam representantes, vendedores dentro da minha barbearia e assusta "quem que é o dono?", "o dono é o (...). " Mas aquele ali?" Muita gente já chegou para conversar com o (...) que é o mais branquinho aqui da turma, "você que é o dono aqui? Eu queria falar com você." "Não, o dono é ele." "Ah, você que é o dono, mas que cabelo doido" (...) até hoje. (Empreendedor A) 
(017) Eu queria ser mais assim otimista, mas eu acho que só se Deus voltar, Jesus Cristo voltar para a Terra, porque do jeito que está não vai melhorar mais não. Por mais que a gente tente se destacar, se mostrar diferente, a cultura do Brasil é essa. Infelizmente a gente é um país, que era para ser um país do negro que foi tomado pelo o branco, e a ideia ficou totalmente a do branco. Por mais que a gente começa se destacar no mercado sempre o que vai vir primeiro é "sabe aquele negão, dono, aquele preto lá, dono, aquele moreninho", sempre vai ser isso. A cultura do Brasil vai ser essa, por mais que a gente tente fazer, abrir o próprio negócio, fazer propaganda, tentar quebrar um pouco o racismo, isso vai ser até não sei quando. (Empreendedor A)

Além do sentimento de pessimismo (e, por que não dizer, um certo sentimento contraditório de resignação) quanto ao futuro, expressado nas linhas anteriores, a seleção lexical do fragmento discursivo (018) parece demonstrar o medo de ocupar (apesar do discurso da luta) determinados espaços sociais tradicionalmente "brancos":

(018) Você acha por quê? Ai, eu não fui pra (endereço) também, que é um lugar que todo mundo quer estar (...) eu tenho até medo das pessoas não aceitarem nós lá, né, de achar assim, eles têm que ficar lá no canto deles, aqui é o nosso espaço. (...) Eles estão invadindo um espaço que é nosso, eles acham que o negro tem que continuar na cozinha, pra ser sincero, o negro tem que continuar na cozinha, o negro tem que continuar na senzala, apanhando até hoje lá no chicote, e assim que o negro, eles acham que tem que continuar (Empreendedora B)

Este fragmento (018) demonstra, sobretudo, o que parece ser uma certa estratégia de "evitamento", por parte dos empreendedores negros pesquisados (e, por que não dizer, da própria população negra), de determinados espaços sociais tendo, como uma de suas consequências diretas, uma realidade de segregação não somente social, mas, também, espacial. Haveria, portanto, uma clara demarcação, no espaço da cidade, de territorialidades raciais que "expulsariam" os empreendimentos gerenciados por negros para fora do centro empresarial (notadamente branco). Esta constatação pode ser observada através da seleção lexical do fragmento (018), na medida em que o endereço supracitado (potencialmente o local onde seria instalada a loja) é "(...) um lugar que todo mundo quer estar", embora a empreendedora B tenha medo de que não fosse bem aceita lá. É interessante apontar, por fim, que a impossibilidade de ocupar determinado território (espacialmente falando) acaba sendo, em certo sentido, no discurso da entrevistada, uma metáfora para as dificuldades de inserção dos negros em outros espaços sociais como a escola e o trabalho.

Portanto, verificam-se evidências variadas da relação entre aspectos objetivos do empreendedorismo e elementos subjetivos intervenientes à ação dos empreendedores negros estudados. Pode-se afirmar, neste sentido, que as situações particulares aqui analisadas e discutidas reverberam uma problemática presente em outros estudos sobre a questão étnicoracial nos estudos organizacionais (CONCEIÇÃO, 2009; ROSA, 2014) e nos estudos em empreendedorismo (HISRICH; BRUSH, 1991; HARVEY, 2005; KÖLLINGER; MINNITI, 2006; OLIVEIRA; PEREIRA; SOUZA, 2013; SINGH; GIBBS, 2013; GIBBS, 2014; REZENDE; MAFRA; PEREIRA, 2018). Contribui-se, assim, para a estruturação de um quadro teórico necessário ao campo, gerando evidências de como todo esse conjunto de ações se manifestam e se estruturam no âmbito da prática de empreendedores negros. 


\section{$5 \quad$ Considerações finais}

O objetivo geral deste trabalho consistiu em analisar a trajetória individual e empresarial de dois empreendedores negros que atuam em uma cidade da região do Triângulo Mineiro, estado de Minas Gerais. Especificamente, buscou-se, compreender o processo empreendedor executado pelos mesmos para criar e desenvolver seus negócios, bem como identificar os desafios e dificuldades enfrentados. Para tanto, foram acessadas, através de uma abordagem qualitativa de investigação apoiada pela estratégia de estudo de casos múltiplos e pela técnica de análise de discurso, as decisões e ações de dois empreendedores negros na criação e desenvolvimento dos negócios a eles vinculados.

Foi possível observar, a partir da análise e discussão dos resultados da pesquisa, que, associado às diferentes trajetórias de identificação e exploração de oportunidades para a criação de novos negócios, parece haver um histórico desafios, discriminações e preconceito racial que permeia as experiências vividas pelo empreendedor e pela empreendedora estudados nos diversos espaços sociais que esses sujeitos frequentaram (escola, trabalho, família). Foi somente a partir de um processo de autorreflexão que os mesmos puderam aceitar-se enquanto negros, buscando expandir tal compreensão para o universo de seus negócios e de suas decisões e ações enquanto empreendedores.

Portanto, conclui-se que a dinâmica particular dos casos estudados revela nuances tanto de elementos objetivos do fenômeno empreendedor, incluindo especificidades de processos empreendedores de criação de negócios, como de elementos subjetivos do empreendedorismo étnico-racial, a partir da problematização da ação empreendedora de negros e dos desafios por eles enfrentados. Com efeito, no âmbito da atuação desses empreendedores e no âmbito de seus empreendimentos, pode-se afirmar que há uma imbricação entre um caráter de luta e de valorização da cultura negra e uma valorização do empreendedorismo enquanto possibilidade de reafirmação enquanto sujeito e enquanto agente inserido em um contexto socioeconômico, buscando estruturar novas formas de identificação e exploração de oportunidades, de atuação no mercado, de concorrência real e simbólica, focando seus esforços em direção a um determinado público específico (negro). No entanto, o preconceito racial e os diferentes tipos de discriminação não deixam de perseguir e se fazer presentes na realidade vivenciada por tais empreendedores mesmo no cotidiano de suas empresas, gerando sentimentos contraditórios de resistência e luta, mas também de pessimismo e resignação quanto ao futuro.

Acredita-se que esta pesquisa tenha lançado algumas luzes sobre especificidades do processo empreendedor de negros, especialmente no que diz respeito a suas imbricações com a realidade cultural brasileira. Neste sentido, a contribuição deste artigo perpassa a ideia de uma afinidade eletiva entre a questão racial e o processo empreendedor, de modo mais específico, e com o próprio fenômeno do empreendedorismo, de modo mais amplo. Não obstante, faz-se necessária a compreensão desta realidade a partir de suas diversas facetas, incluindo outras perspectivas de análise e de outros quadros teóricos associados à temática do empreendedorismo. Em uma perspectiva de consubstancialidade, o processo empreendedor poderia passar também a ser visto, especialmente no que tange a realidade brasileira, a partir das diversas desigualdades sociais que permeiam a sociedade brasileira (gênero, raça, classe social, etc.), fato que revela possibilidades de novas pesquisas sobre o tema aqui explorado. 
ALVES, M. A.; GALEÃO-SILVA, L. G. A crítica da diversidade nas organizações. Revista de Administração de Empresas, v. 44, n. 3, p. 20-29, jul./set. 2004.

ARMAN, A. P. Empreendedorismo entre mulheres negras na cidade de São Paulo. Revista de Administração do UNISAL, v. 5, n. 8, p. 64-82, 2015.

BORGES, A. F.; ENOQUE, A. G.; KATRIB, C. M. I.; GONÇALVES, L. R. D. Práticas Organizativas: Um Estudo sobre o Congado na Região do Triângulo Mineiro. Revista Interdisciplinar de Gestão Social, v. 5, n. 1, p. 129-151, 2016.

BORGES, A. F.; LIMA, J. B; BRITO, M. J. Fundamentos da Pesquisa em Empreendedorismo: aspectos conceituais, teóricos, ontológicos e epistemológicos. In: ENCONTRO DA ASSOCIAÇÃO NACIONAL DE PÓS-GRADUAÇÃO E PESQUISA EM ADMINISTRAÇÃO, 41, 2017, São Paulo. Anais... Rio de Janeiro: ANPAD, 2017.

BUSENITZ, L. W. et al. Entrepreneurship research (1985-2009) and the emergence of opportunities. Entrepreneurship Theory and Practice, v. 38, n. 5, p. 981-1000, set. 2014.

BYGRAVE, W. D. The entrepreneurship paradigm (I) revisited. In: NEERGAARD, H.; ULHØI, J. P. (Org.). Handbook of Qualitative Research Methods in Entrepreneurship. Cheltenham: E. Elgar, 2007. cap. 2, p. 17-48.

CARLSSON, B. et al. The evolving domain of entrepreneurship research. Small Business Economics, v. 41, n. 4, p. 913-930, 2013.

CERQUEIRA, V. L. de. A inserção do negro no mercado de trabalho brasileiro na década passada. 2012. 61 f. Monografia (Graduação em Economia)-Universidade Estadual de Campinas, Campinas, 2012.

CHARAUDEAU, P.; MAINGUENEAU, D. Dicionário de Análise do Discurso. 3.ed. São Paulo: Editora Contexto, 2014. 554 p.

COELHO JÚNIOR, P. J. Executivos negros: racismo e diversidade no mundo empresarial uma abordagem sócio-antropológica. 2011. 553 p. Tese (Doutorado em Antropologia Social)Universidade de São Paulo, São Paulo, 2011.

CONCEIÇÃO, E. B. A negação da raça nos estudos organizacionais. In: ENCONTRO DA ASSOCIAÇÃO NACIONAL DE PÓS-GRADUAÇÃO E PESQUISA EM ADMINISTRAÇÃO, 33., 2009, São Paulo. Anais... ANPAD: Rio de Janeiro, 2009.

CORBIN, J.; STRAUSS, A. Pesquisa Qualitativa: Técnicas e procedimentos para o desenvolvimento de teoria fundamentada. 2. ed. São Paulo: Bookman, 2008. 146 p.

COSTA, S. G.; FERREIRA, C. S. Diversidade e minorias nos estudos organizacionais brasileiros: presença e lacunas na última década. In: ENCONTRO DE ESTUDOS ORGANIZACIONAIS, 4, 2006, Curitiba; Anais... ANPAD: Rio de Janeiro, 2006. CD-ROM. CRUZ, E. P.; FALCÃO, R. P. Q. Revisão bibliométrica no tema empreendedorismo imigrante e étnico. Revista Internexus, v. 11, n. 3, p. 78-94, set./dez. 2016.

DAVIDSSON, P. Entrepreneurial opportunities and the entrepreneurship nexus: a reconceptualization. Journal of Business Venturing, v. 30, n. 5, p. 674-695, set. 2015.

DENZIN, N. K.; LINCOLN, Y. S. O planejamento da pesquisa qualitativa: Teorias e Abordagens. 2. ed. São Paulo: Bookman, 2006. 217 p.

ECKHARDT, J. T.; SHANE, S. Opportunities and entrepreneurship, Journal of Management, v. 29, n. 3, p. 333-349, jul. 2003. 
FILION, L. J. Diferenças entre sistemas gerencias de empreendedores e operadores de pequenos negócios. Revista de Administração de Empresas, v. 39, n.4, p. 6-20, 1999a.

FILION, L. J. Empreendedorismo: empreendedores e proprietários-gerentes de pequenos negócios. Revista de Administração, v. 34, n.2, p. 5-28, 1999 b.

FIORIN, J. L. Elementos de Análise do Discurso. São Paulo: Contexto, 2014. 126 p.

FLEURY, M. T. L. Gerenciando a diversidade cultural: experiências de empresas brasileiras.

Revista de Administração de Empresas, v. 40, n. 3, p. 18-25, jul./set. 2000.

GARTNER, W. B. Entrepreneurship as organization creation. In: HJORTH, D. (Org.). Handbook on Organisational Entrepreneurship. Cheltenham: E. Elgar, 2012. cap. 1, p. 21 30 .

GIBBS, S. R. The bitter truth: a comparative analysis of black male and black female entrepreneurs. Journal of Developmental Entrepreneurship, v. 19, n. 1, p. 1-18, 2014.

GLOBAL ENTREPRENEURSHIP MONITOR (GEM). Empreendedorismo no Brasil: 2017. Curitiba: IBQP, 2018.

GOMES, A. F.; LIMA, J. B.; CAPPELlE, M. C. A. Do Empreendedorismo à Noção de Ações Empreendedoras: Reflexões Teóricas. Revista Alcance, v. 20, n. 2, p. 203-220, 2013.

HABER, S.; REICHEL, A. The cumulative nature of the entrepreneurial process: the contribution of human capital, planning and environment resources to small business performance. Journal of Business Venturing, v. 22, n. 1, p. 119-145, jan. 2007.

HARVEY, A. M. Becoming entrepreneurs: intersections of race, class, and gender at the black beauty salon. Gender \& Society, v. 19, n. 6, p. 789-808, 2005.

HESSELS, J.; VAN GELDEREN, M.; THURIK, R. Entrepreneurial aspirations, motivations, and their drivers. Small Business Economics, v. 31, n. 3, p. 323-339, mai. 2008.

HISRICH, R. D.; BRUSH, C. G. Characteristics of the minority entrepreneur. Journal of Small Business Management, v. 24, n. 4, p. 1-8, 1991.

INMAN, K. Women's Resources in Business Start-Up: a study of black and white women entrepreneurs. Londres: Routledge, 2000. 344 p.

JACK, S. L.; ANDERSON, A. R. The effects of embeddedness on the entrepreneurial process. Journal of Business Venturing, v. 17, n. 5, p. 467-487, out. 2002.

JAIME, P. Executivos negros: Racismo e diversidade no mundo empresarial. São Paulo: EdUSP, 2016.

KÖLLINGER, P.; MINNITI, M. Not for lack of trying: American entrepreneurship in black and white. Small Business Economics, v. 27, n. 2, p. 59-79, 2006.

LEEUWEN, T.V. Discourse and Practice: New tools for critical discourse analysis. New York: Oxford University Press, 2008. 172 p.

LEYDEN, D. P.; LINK, A. B. Toward a Theory of the Entrepreneurial Process. Small Business Economics, v. 44, n. 3, p. 475-484, 2015.

LIMA, J. B. Ações Empreendedoras e Práticas de Pesquisa em Empreendedorismo. In: GIMENEZ, F.; FERREIRA, J. M.; RAMOS, S. C. (Orgs.). Empreendedorismo e Estratégia de Empresas de Pequeno Porte. Curitiba: Editora Champagnat, 2010. p. 25-40.

LOPES, R. M. A.; LIMA, E. Desafios atuais e caminhos promissores para a pesquisa em empreendedorismo. Revista de Administração de Empresas, v. 59, n. 4, p. 284-292, 2019.

MONTEIRO, J. A. A questão racial e a administração de recursos humanos nas empresas brasileiras. Revista de Administração de Empresas, v. 29, n. 1, p. 20-29, jan./mar. 1989. 
MOROZ, P. W.; HINDLE, K. Entrepreneurship as a process: toward harmonizing multiple perspectives. Entrepreneurship Theory and Practice, v. 36, n. 4, p 781-818, 2012.

NASSIF, V. M. J.; GHOBRIL, A. N.; SILVA, N. S. da. Understanding the entrepreneurial process: a dynamic approach. Brazilian Administration Review, v. 7, n. 2, p. 213-226, abr. 2011.

OLIVEIRA, J. S.; PEREIRA, J. A.; SOUZA, M. C. D. Empreendedorismo, cultura e diversidade: a participação de empreendedores negros nas atividades empreendedoras no Brasil no período de 1990 a 2008. Revista Contemporânea de Economia e Gestão, v. 11, n. 2, p. 7-30, jul./dez. 2013.

PAIVA JUNIOR, F. G. de. O empreendedorismo na ação de empreender: uma análise sob o enfoque da fenomenologia sociológica de Alfred Schütz. 2004. 382 p. Tese (Doutorado em Administração) - Universidade Federal de Minas Gerais, Belo Horizonte.

PÊCHEUX, M. Análise de Discurso. 4. ed. Campinas: Pontes Editores, 2014. 315 p.

PREISENDÖRFER, P.; BITZ. A.; BEZUIDENHOUT, F. J. In search of black entrepreneurship: why is there a lack of entrepreneurial activity among the black population in South Africa. Journal of Developmental Entrepreneurship, v. 17, n. 1, p. 1-18, 2012.

ROSA, A. R. Relações raciais e estudos organizacionais no Brasil. Revista de Administração Contemporânea, v. 18, n. 3, p. 240-260, mai.jun. 2014.

SHANE, S. Reflections on the 2010 AMR decade award: delivering on the promise of entrepreneurship as a field of research. Academy of Management Review, v. 37, n. 1, p. 1020, jan. 2012.

SHANE, S.; VENKATARAMAN, S. The promise of entrepreneurship as a field of research. Academy of Management Review, v. 25, n. 1, p. 217-226, 2000.

SINGH, R. P.; GIBBS, S. R. Opportunity recognition processes of black entrepreneurs. Journal of Small Business \& Entrepreneurship, v. 26, n. 6, p. 643-659, 2013.

SULLIVAN, D. M. Minority entrepreneurs: more likely to try, but less likely to succeed? Academy of Management Perspectives, v. 21, n. 1, p. 78-79, 2007.

VALE, G. M. V. Empreendedor: Origens, Concepções Teóricas, Dispersão e Integração. Revista de Administração Contemporânea, v. 18, n. 6, p. 874-891, 2014.

YIN, R. K. Estudo de caso: Planejamento e métodos. 2.ed. Porto Alegre: Bookman. 2001. $246 \mathrm{p}$. 